\title{
REHABILITATION AND IMPROVEMENT OF FATIGUE LIFE OF WELDED JOINTS BY ICR TREATMENT
}

\author{
Kentaro Yamada ${ }^{1, *}$, Toshiyuki Ishikawa ${ }^{2}$ and Takumi Kakiichi ${ }^{3}$ \\ ${ }^{1}$ Professor Emeritus, Nagoya University, Japan \\ Advisor, Central Nippon Highway Engineering Nagoya, Co. Ltd., Japan \\ ${ }^{2}$ Dept. of Urban Management, Kyoto University, Japan \\ ${ }^{3}$ JFE Engineering Corporation, Japan \\ *(Corresponding author: E-mail: k.yamada.e@c-nexco-hen.jp)
}

\begin{abstract}
Over 150,000 highway bridges exist in Japan and about 47 percent of the bridges will be over 50 years old in 2026. The Ministry of Land, Infrastructure, Transport and Tourism (MLIT) launched nation-wide projects to inspect and to establish maintenance plans. About one half of the highway bridges were steel bridges with concrete slabs. Due to heavy truck traffics being operated in or between industrial cities, some of which were illegally overloaded, severe deteriorations to concrete slabs and fatigue cracks in steel girders have been observed. Fatigue cracks in orthotropic steel decks were also found. It is urgent to tackle such fatigue cracks observed in welded joints of steel bridges. Various attempts have been made in Japan to repair and rehabilitate such fatigue cracked members. One is to improve fatigue strength of welded joints in existing bridges, and the other is to repair and rehabilitate cracked members. The latter were, for example, re-welding cracked joints, strengthening by using high strength bolted splices, adding glue to cracks, rehabilitating by gluing CFRP. The authors developed a technique, so-called ICR Treatment, or Impact Crack Closure Retrofit treatment, where fatigue cracks was closed by giving plastic yielding at plate surface near fatigue cracks. Since fatigue cracks do not open due to applied stress ranges, the cracks either do not propagate, or propagate much slower, to prolong remaining fatigue life of the bridges. Fatigue tests were carried out on various welded joints to show how fatigue life was improved by applying the ICR treatment to the cracked welded joints.
\end{abstract}

Keywords: Fatigue test, Welded joint, Crack, Rehabilitation, Improvement

DOI: $10.18057 /$ IJASC.2015.11.3.4

\section{INTRODUCTION}

Various types of fatigue cracks have been observed in steel highway bridges in Japan. At first, they were due to inappropriate welded joints associated with insufficient knowledge about fatigue. Then, increase in number and weight of trucks caused larger stress ranges and their number of cycles, and caused fatigue cracks to welded joints. In order to prevent such fatigue cracks, fatigue design was adapted to the design specification of highway bridges by Japan Road Association in 2002. It was enhanced further in 2012 Specifications.

Three main factors are normally considered in fatigue of welded structures. They are structural details, applied stress ranges and their number of cycles. When the structures or the welded joints to be considered are subjected to certain levels of stress ranges and their number of cycles, structural detail with higher fatigue strength is to be used to prevent fatigue crack. Alternative is to improve fatigue strength of the welded joints.

Various fatigue strength improvement techniques are developed in the past, such as grinding weld toe to reduce stress concentration, peening technique to round the weld toe and to introduce 
compression residual stress (Haagensen et al. [1], Anami et al. [2], Branco et al. [3]). More advanced techniques are UIT (Ryo et al. [4], Tominaga et al. [5]) or HFP (Pedersen et al. [6]), which is the similar technique to the peening, but with less noise, was now widely used in fabrication process. High compressive residual stress is the main contributor to the improvement of fatigue strength.

When fatigue cracks are found in existing highway bridges in Japan, they are often leave as they are, and monitored until the cracks grow to rather larger crack sizes. However, larger fatigue cracks often caused expensive repair and retrofitting works. Therefore, simple and inexpensive repair technique is requested from the field.

We have developed a technique called ICR treatment, or Impact Crack Closure technique, to repair fatigue cracks (Yamada et al. [7]). It used small pneumatic tool to hit surface of steel plate to introduce plastic yielding. It will help to create high compressive residual stress at weld toe, or to close fatigue crack at its surface. Various fatigue tests were carried out at Nagoya University, where the authors belonged until 2010 (Yamada et al. [8]). Some of the fatigue test results of ICR treated specimens were described hereafter.

\section{ICR TREATMENT}

The ICR treatment, or Impact Crack Closure technique, is a technique to introduce plastic yielding of steel plate near fillet weld toe or near fatigue cracks. It uses a pneumatic tool to hit steel surface and an air compressor, as shown in Figure 1.
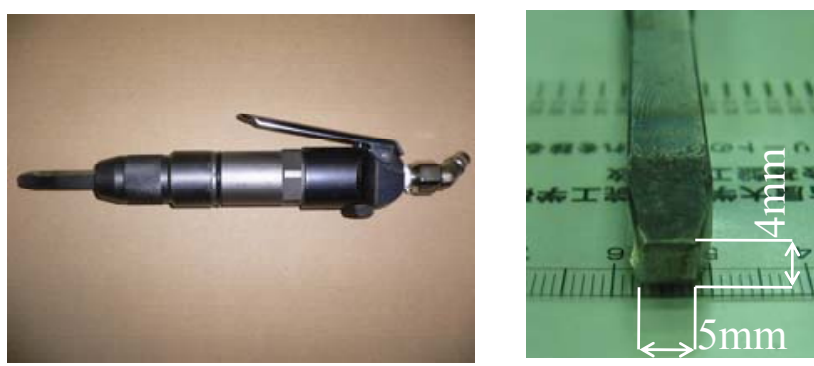

(a) Pneumatic Tool and Tip Figure 1. Tools Used for ICR Treatment
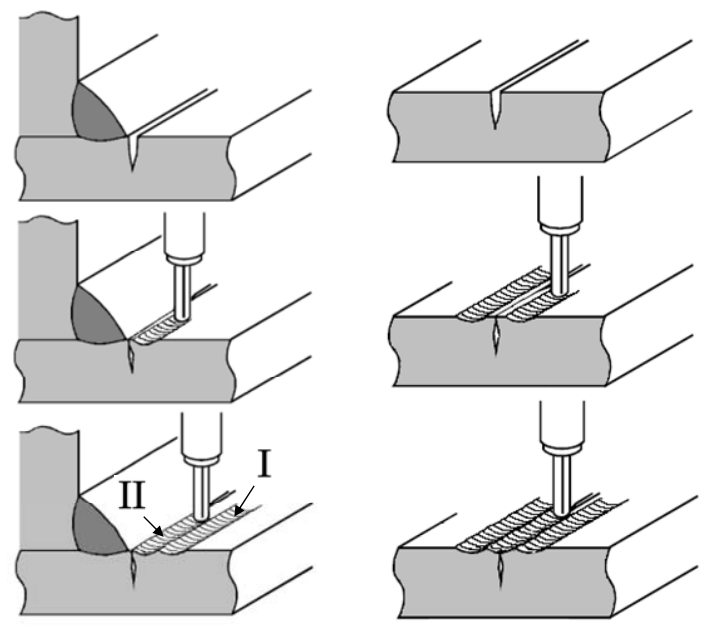

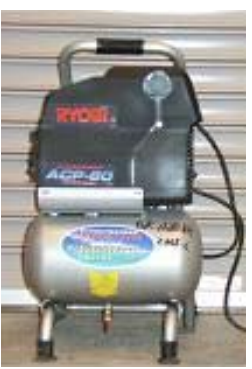

(b) Air Compressor 
(a) Small Crack at Weld Toe (b) Crack Propagating in Plate

Figure 2. Schematic View of ICR Treatment for Fatigue Crack
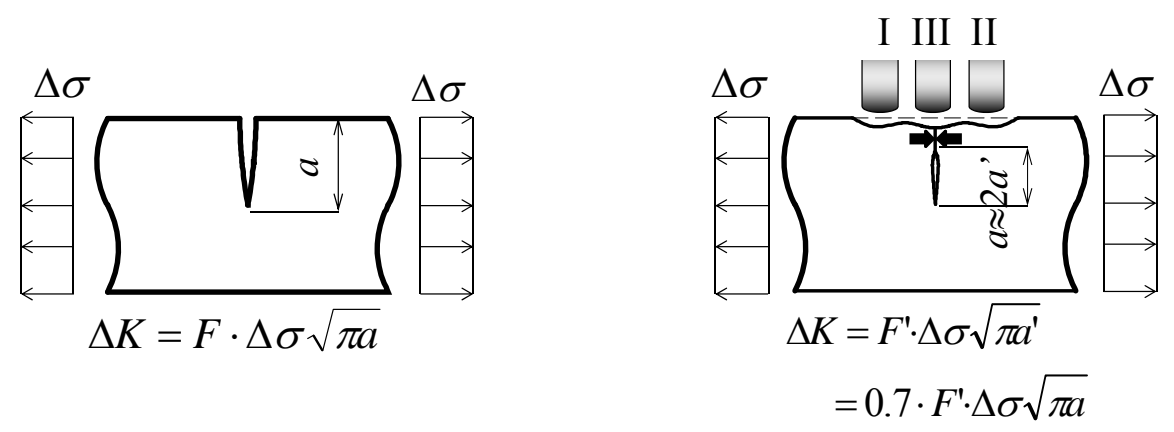

(a) Edge Crack $\quad$ (b) Crack When Crack Remain Closed Due to Applied Load Figure 3. Schematic View of Repair of Fatigue Crack Using ICR Treatment

The basic concept of the ICR treatment is based on fracture mechanics consideration, as described in Figures 2 and 3. If a crack is found at weld toe, the ICR treatment is carried out at plate near the crack to cause plastic yielding. The surface of the crack is then closed at the surface. If one can create enough plastic yielding, then the crack do not open due to applied stresses. Two steps can be carried out, I and II as shown in Figure 2, to create even larger compressive plastic yielding at the weld toe, if one needs. When the crack propagates to plate, then the ICR treatments are carried out from both sides and on the top of the crack.

The mechanism of the repair of fatigue crack by ICR treatment is briefly described in Figure 3, where a plate with an edge crack is subjected to tension stresses. When the crack is closed and do not open due to the applied stress, the crack can be considered as an internal crack. Then the crack size can be considered as a half of that of the edge crack. Stress intensity factor range, $\Delta K$, which expresses severity of crack tip according to fracture mechanics, becomes about 70 percent of the edge crack. Fatigue crack growth rate, $\mathrm{d} a / \mathrm{d} N$, of steel is a function of $\Delta K$ and is proportional to the power of three of $\Delta K$. Therefore, $\mathrm{d} a / \mathrm{d} N$ slows down to 0.34 times of the one for the edge crack. It implies that the fatigue crack propagation life becomes about three times longer. If the $\Delta K$ becomes less than threshold value of stress intensity factor range, $\Delta K_{\mathrm{th}}$, below which crack do not propagate, the fatigue life after the ICR treatment becomes infinite.

The technique can be also used to improve fatigue strength of weld toes, since large compressive residual stress can be introduced to the weld toe in the same way as the peeing technique and the UIT, although weld toe profiles are not rounded.

\section{FATIGUE TESTS OF VARIOUS WELDED DETAILS WITH SMALL CRACKS}

Fatigue tests of various welded joints were carried out to verify the effectiveness of the ICR treatment, as shown in Table 1. They were a) bead-on plates with a notch, b) out-of-plane gusset specimens, c) plate edge gusset welded joints ( $\mathrm{T}$ joints), and d) fillet-welded joints. All these tests were carried out in plate-bending type of loading, with plate bending fatigue testing machines developed at Nagoya University (Yamada et al. $[9,10]$ ). A photo and a schematic illustration of the plate bending fatigue testing machine are shown in Table 1, where a vibrator, a motor with two 
eccentric mass on both side gives repeated loading to specimens. Springs are to give initial static loading in order to obtain desired stress ratio. Strain gages were monitored during fatigue tests to obtain stress ranges to be used for S-N curves. Also attached to the specimens were thin copper wires of $0.04 \mathrm{~mm}$ diameter at designated points. The copper wires were connected to the fatigue testing machine. When fatigue crack cut the copper wires, the fatigue testing machine stopped. For example, the copper wires were glued to weld toe, $10 \mathrm{~mm}$ from weld toe, and $30 \mathrm{~mm}$ of the specimens with out-of-plane gusset. These copper wires helped us to stop the fatigue testing machine automatically at designated crack sizes.

Table 1. Fatigue Test Specimens with and Without Fatigue Crack

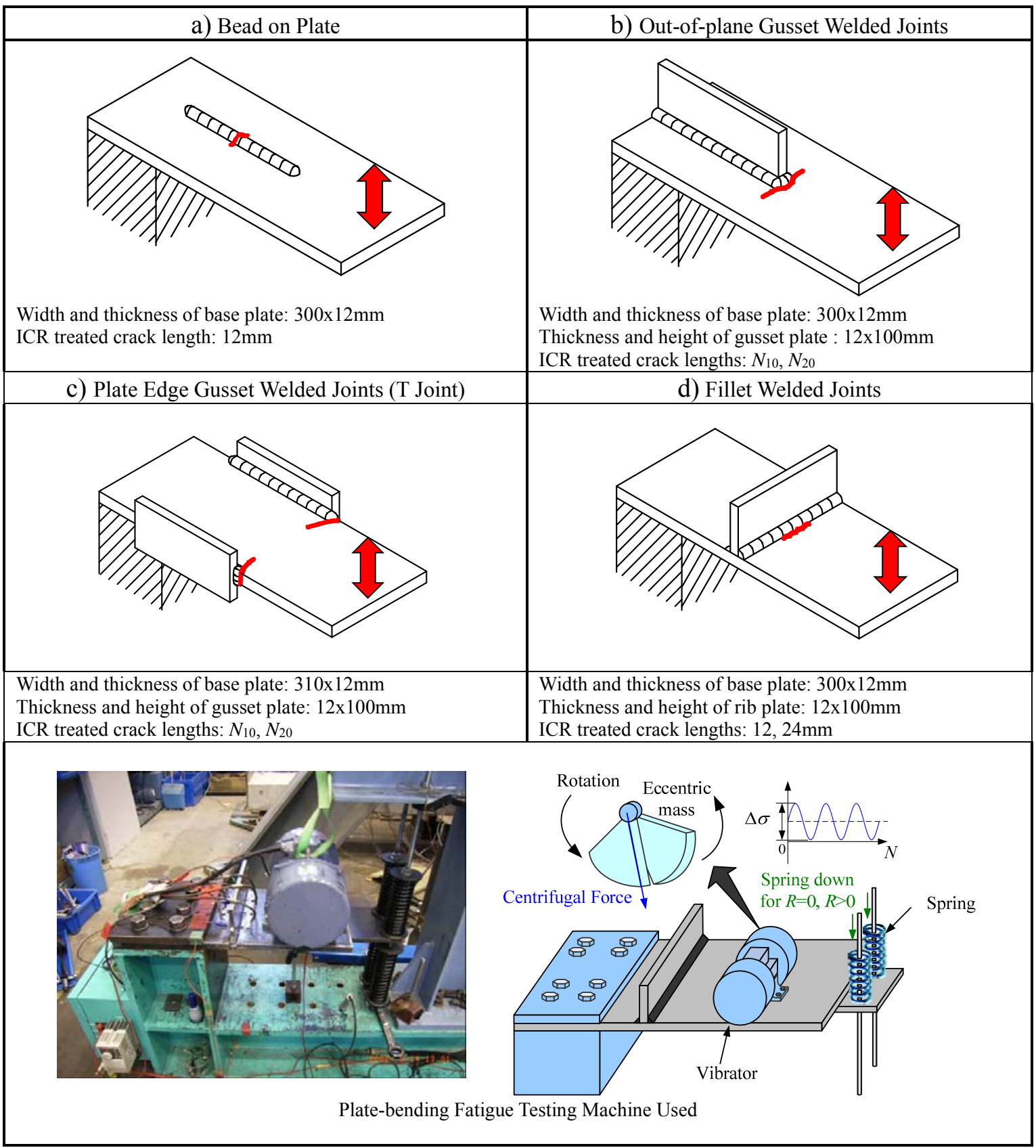




\subsection{Fatigue Test Results of Bead-on Plate}

The first test on verification of ICR treatment was carried out on bead-on plate, which had a notch at a weld bead at center of the plate. Fatigue crack of a semi-elliptical shape was first developed at the notch, and then the ICR treatment was carried out to close the crack opening. Then, the fatigue test was continued. The fatigue test data of ICR treated specimens showed much longer fatigue life, compared with the data without the ICR treatment, as shown in Figure 4.

After the fatigue tests, the section of the test specimen with ICR treatment was cut-out to see how the crack was closed with the ICR treatment. The section is shown in Figure 4. The ICR treatment was found to close the fatigue crack up to about $1 \mathrm{~mm}$ from the surface.
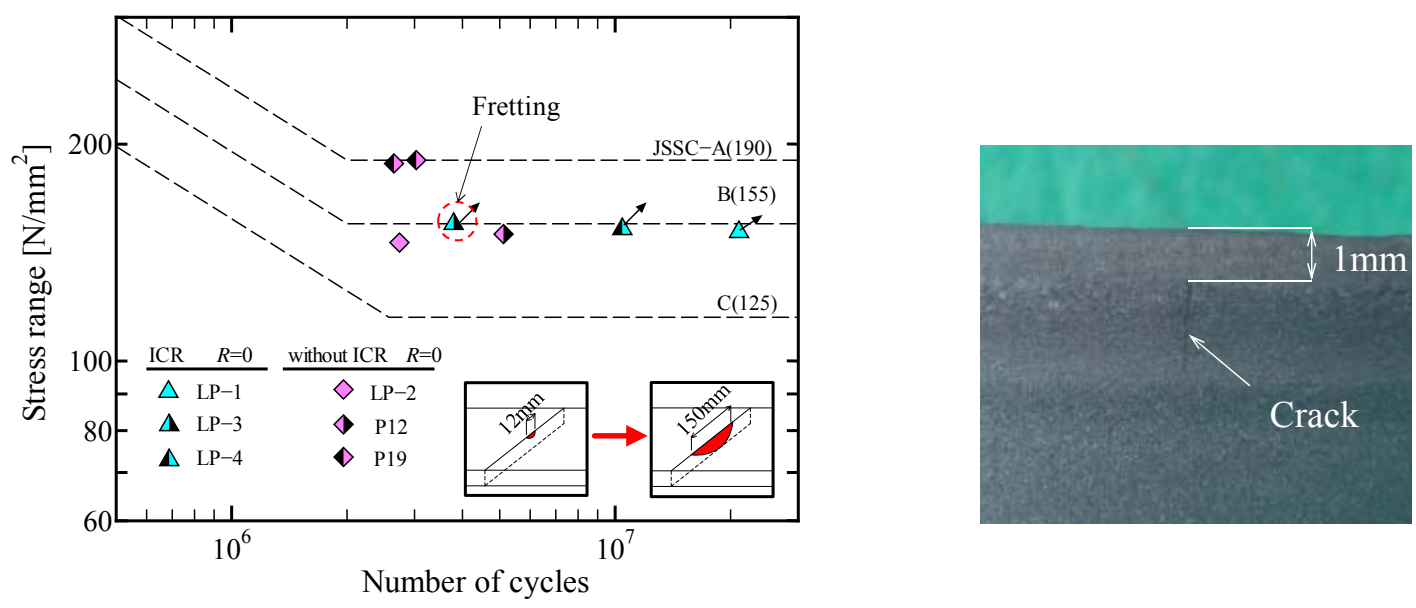

Figure 4. Fatigue Test Results of Bead-on Plate with or without ICR Treatment and Internal Crack

\subsection{Fatigue Test Results of Out-of-Plane Gusset}

Fatigue tests were carried out for out-of-plane gusset welded joints in bending. First, fatigue cracks were developed at weld toe, and propagated around the turn-around weld of the gusset end, as shown in Figure 5. The crack at this stage was defined as $N_{b}$. Then, fatigue crack separated from the weld toe, and propagated to main plate. When the crack became about $10 \mathrm{~mm}$ long from weld toe, the crack was defined as $N_{10}$. The crack was detected by copper wire of $0.04 \mathrm{~mm}$ diameter glued at designated location. When the fatigue crack reached and cut the copper wire, it stopped the fatigue testing machine.

The ICR treatment was carried out around fillet weld of the turn-around weld of gusset end for $N_{b}$ crack, as shown in Figure 5. For $N_{10}$ crack, the ICR treatment was first applied to both sides of the crack in base plate, on top of the crack, and then along the turn-around weld, as shown by I, II, III, and IV in Figure 5.

Fatigue test results showed the significant improvement of fatigue life due to the ICR treatment, as shown in Figure 6. For example, when the ICR was applied to $N_{b}$ crack, all test data showed lives over 10 million cycles, while the specimens failed at less than 3 million cycles without the ICR treatment. In order to see the fracture surface, a specimen was re-tested with higher stress range, 
and it failed at around Stress Category $\mathrm{C}$ of Fatigue Design Recommendations by the Japanese Society of Steel Construction (JSSC [11]).

The same results were observed for the $N_{10}$ cracks. When the $N_{10}$ crack was retrofitted by the ICR treatment, the fatigue life became longer than 10 million cycles.
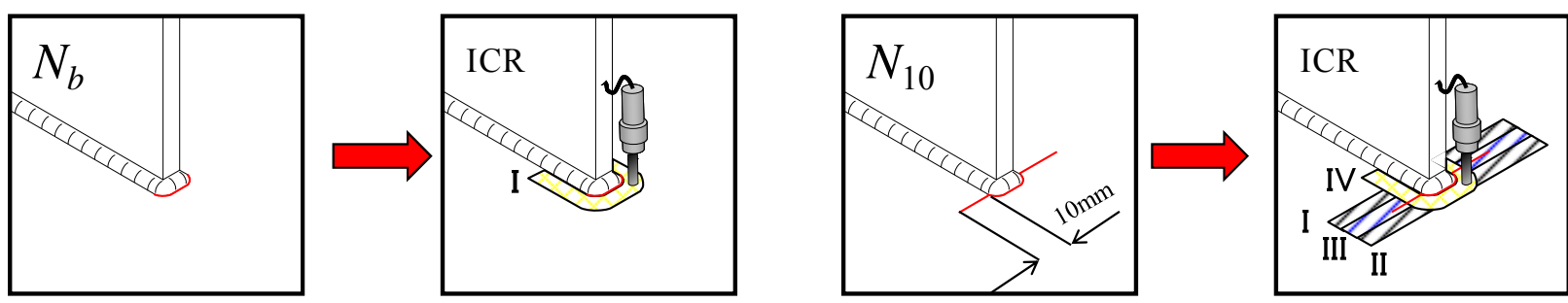

Figure 5. Definition of Crack Sizes and ICR Treatments at $N_{b}$ and $N_{10}$

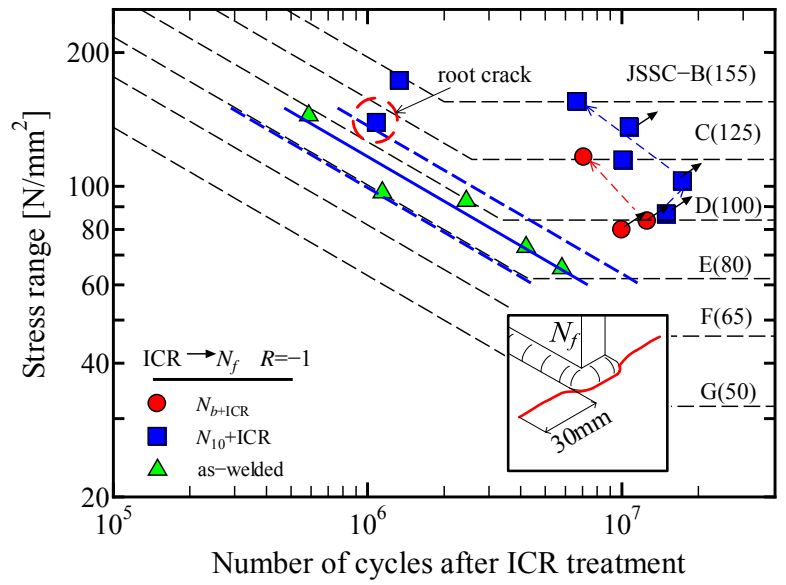

Figure 6. Fatigue Test Results of Out-of Plane Gusset with ICR Treatment at $N_{b}$ and $N_{10}$

\subsection{Fatigue Test Results of Plate Edge Gusset Welded Joints (T joints)}

Fatigue cracks are normally initiated and propagated from fillet weld toes at the end of gussets welded perpendicular to the plate edge. Normally four fatigue cracks were observed at both sides and surface and back surface of the main plate. These cracks were ICR treated when they were 10 $\mathrm{mm}$ long $\left(N_{10}\right.$ crack) and when they were $20 \mathrm{~mm}$ long $\left(N_{20} \mathrm{crack}\right)$. Fatigue test results are shown in Figure 7. Base data for $\mathrm{T}$ joints in as-welded condition are shown with scatter band of S-N curves.

When all four cracks were ICR treated, regardless of the crack sizes, i.e. $N_{10}$ or $N_{20}$, the test data showed the life more than 10 million cycles. It implies that the beneficial effect of the ICR treatment is significant. However, when the ICR treatment was applied only surface of the plate, fatigue cracks in back surface propagated and the specimen failed, although it was tested in tension-tension stress condition, or stress ratio $R>0$. Yet, it showed life corresponding to the upper bound of the specimens tested in as-welded condition. 

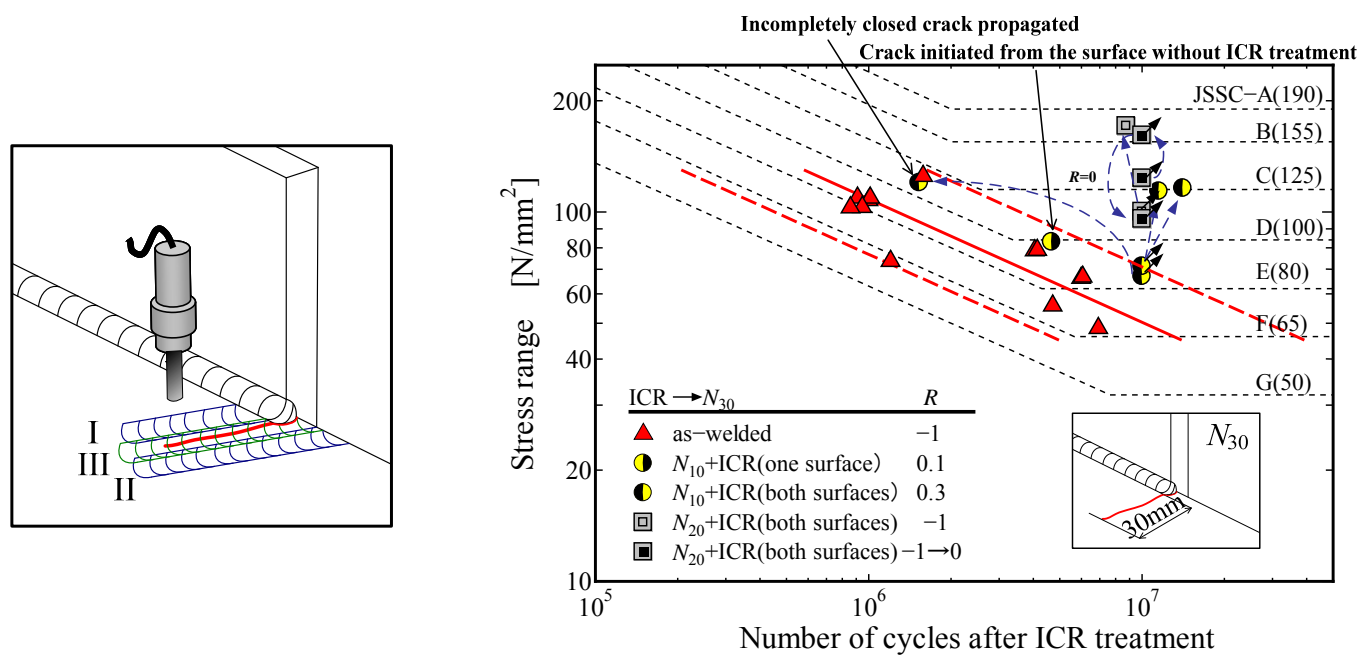

Figure 7. Fatigue Test Results of T joints with ICR Treatment

\subsection{Fatigue Test Results of Fillet Welded Joints}

Fillet welded specimens often showed fatigue cracks along the fillet weld toe. In order to control the size of the semi-elliptical cracks at the fillet weld toe, the ICR treatment was carried out first along the fillet weld toe, but leaving untreated zones at the center of the main plate by $12 \mathrm{~mm}$ or 24 $\mathrm{mm}$, as shown in Figure 8. After the preliminary fatigue tests, fatigue cracks of $2 b=12 \mathrm{~mm}$ or 24 $\mathrm{mm}$ were observed along the fillet weld toe.
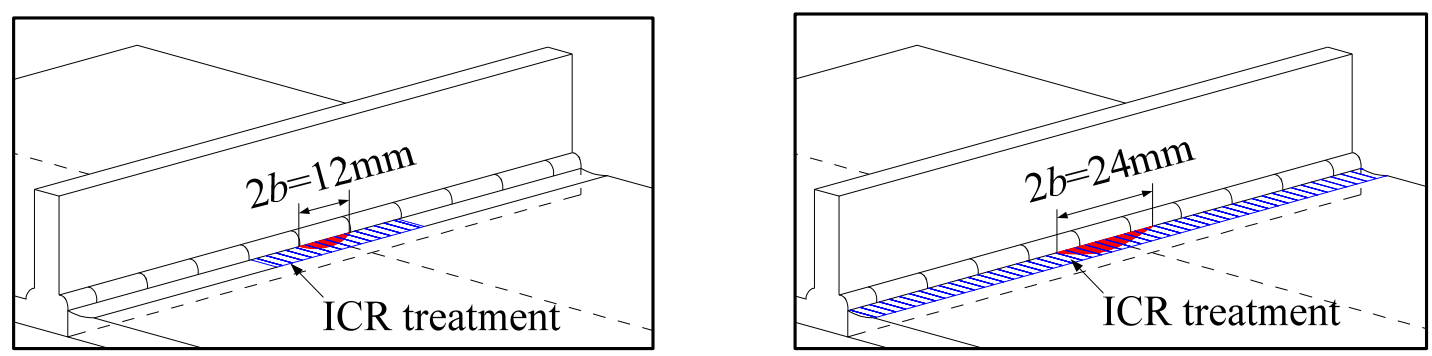

Figure 8. ICR Treatment for Fillet Welded Joints

Then, the ICR treatments were carried out. For the $12 \mathrm{~mm}$ crack, the ICR treatment was carried out along the crack and $20 \mathrm{~mm}$ more on both sides. The fatigue life after retrofitting was longer than the upper bound of the as-welded specimens, and retrofitting work was proved to be effective, as shown in Figure 9. By observation of fatigue fracture surface, the $12 \mathrm{~mm}$ crack, which initially introduced and ICR-treated, did not propagate. A new fatigue crack initiated and propagated from the weld toe at the point where the ICR treatment was terminated. We found that the beneficial compressive residual stress was diminished by the second application of the ICR treatment.

For the $24 \mathrm{~mm}$ crack, we applied the ICR treatment along the whole length of fillet weld toe. Then, no fatigue crack propagation was observed even over 10 million cycles of loading. The applied stress range was increased, but again no fatigue crack propagation was observed over 10 million cycles. Some specimens failed at the support due to fretting fatigue. 
The test result shows that ICR treatment is effective to retrofit cracks at fillet weld toe. If the ICR treatment is applied along whole length of the fillet weld, not only at the crack location, the beneficial effect is more significant.

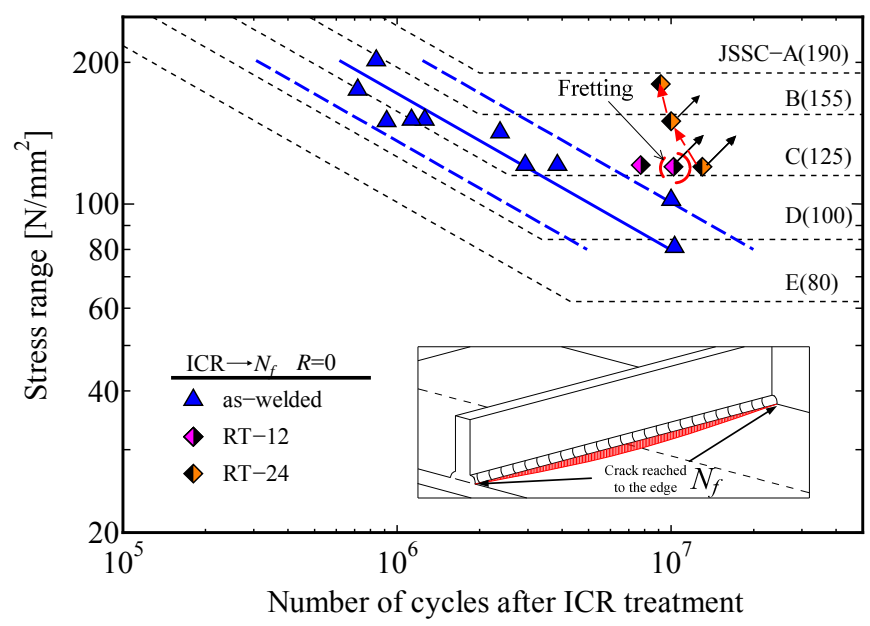

Figure 9. Fatigue Test Results of Fillet Welded Joints with ICR Treatment

\section{PRACTICAL APPLICATION OF ICR TREATMENT IN EXISTING BRIDGES}

During the process of developing the ICR treatment, we have carried out fatigue tests of specimens in as-welded conditions. All test data showed significant increase in fatigue strength, and the technique is proved to be applicable to fatigue strength improvement of existing bridges. We have applied the ICR treatment to fatigue prone details in several highway bridges with orthotropic steel decks.

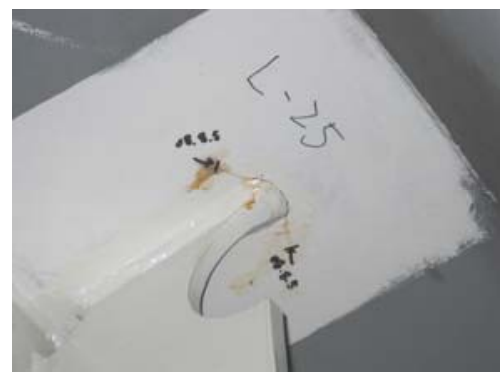

(a) Fatigue Crack at End of Vertical Stiffener

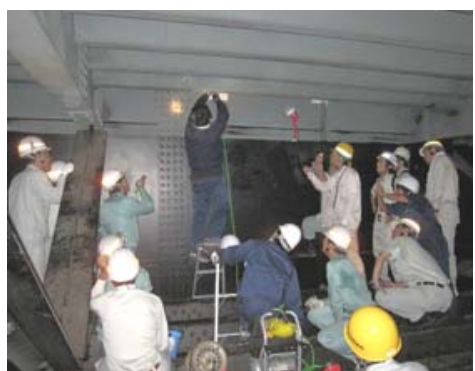

(b) Demonstration of ICR Treatment

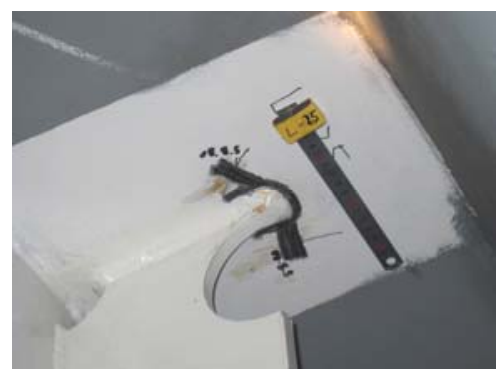

(c) ICR Treated Crack

Figure 10. Fatigue Cracks in Orthotropic Steel Decks Retrofitted by ICR Treatment

The ICR treatments were also used to repair and retrofit fatigue cracks observed at upper ends of vertical stiffeners, which were often observed in Japanese orthotropic steel decks (Yamada \& Ya [12]), as shown in Figure 10. The details were once retrofitted by drilling circular holes near the cracks. The circular holes were expected to reduce stress concentration at the end of the vertical stiffeners, and hence reduced fatigue crack growth rates. Therefore, the fatigue cracks were left as they were. We applied the ICR treatment to seven locations of these cracks on March 2009. 
The ICR treatments for these cracks took several minutes each, not counting preparation stages. The time needed for ICR treatment was much less than other retrofitting measures. Other retrofitting measure, for example adding high strength bolted splice plates, needed normally several hours with closure of traffic lane.

Stress measurements were carried out in order to prove that the ICR treated cracks remained closed under service loading. The strain curves due to three axle trucks are shown in Figure 11(a). They were measured in deck plate at $12 \mathrm{~mm}$ off from the turn-around weld.

Four strain waves were measured at the locations where a) as-welded (no crack) one, b) with $N_{10}$ crack, c) with ICR treated $N_{b}$ crack, and d) with ICR treated $N_{10}$ crack. The strain curve for the as-welded one showed compressive strain due to rear wheel, while that for $N_{10}$ crack showed tensile strain due to the rear wheel. When the ICR treatment were carried out for the $N_{b}$ and $N_{10}$ cracks, the strain waves due to rear wheel became compressive strain, in the same manner as the as-welded one. It implies that the ICR treated details behaved in the same manner as the as-welded condition. Periodic monitoring of the strain was carried out after six month and 1.5 years. As shown in Figures 11(b) and 11(c), the strain measured waves showed the same tendency as the strain measured after ICR treatment shown Figure 11(a).

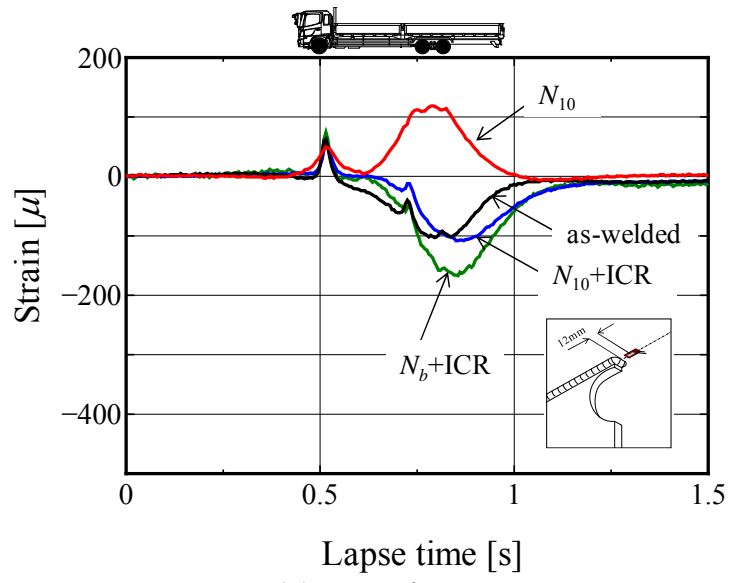

(a) March 2009

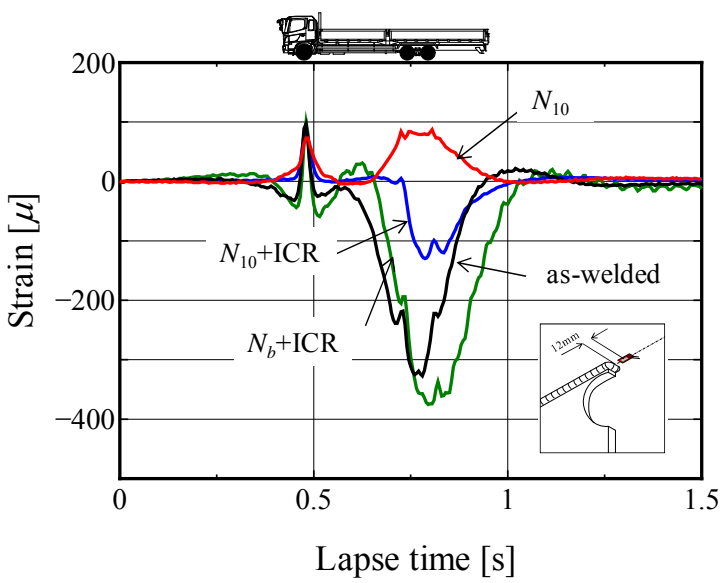

(b) September 2009

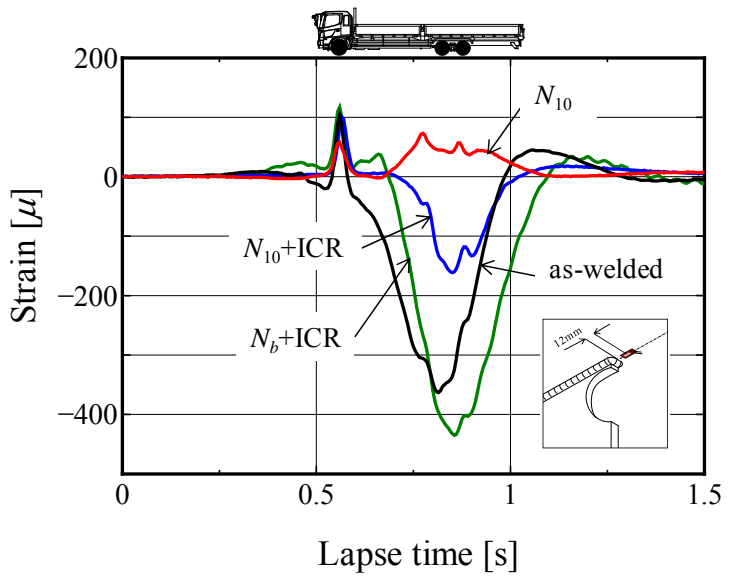

(c) August 2010

Figure 11. Strains Measured under Service Loading 


\section{CONCLUSIONS}

Fatigue cracks were observed in Japanese highway bridges, especially in orthotropic steel decks, in the past two decades. Increase in truck weight and their numbers, including over loaded trucks, were one cause of those fatigue cracking. Efficient and economical retrofitting measures were urgently requested by bridge owners. Various fatigue strength improvement techniques, such as grinding weld toe, peening technique and UIT, can be used to improve fatigue resistance of the existing bridges. Repair methods, such as adding splice plates with high strength friction type bolts, were often used for retrofitting fatigue cracked members.

We have developed a technique called ICR treatment, or Impact Crack Closure Retrofit treatment, which enabled us to retrofit fatigue cracks when they are small. When fatigue cracks are detected, the opening of the crack is closed by giving plastic yielding near the crack. If the crack is not open due to applied stress ranges, the crack growth rates decreases, which yields to increase in fatigue crack propagation life. If the situation meets, such as the stress intensity factor range becomes less than its threshold value, the fatigue cracks do not propagate. Fatigue tests of various details showed significant increase in fatigue life after the ICR treatment. Fracture mechanics consideration also proves the mechanism of the phenomena.

In order to apply plastic yielding near the crack surface, commercially available pneumatic tools can be used. The ICR treatment takes a few minutes to retrofit one crack, and it is economical way to retrofit fatigue cracks. The ICR treatment was applied to fatigue cracks developed at the upper ends of vertical stiffeners of orthotropic steel decks. Monitoring the ICR treated cracks also proved that the technique can be applied to fatigue cracks in existing members.

\section{ACKNOWLEDGMENTS}

The authors acknowledge all former graduate students of Nagoya University to contribute the fatigue tests of welded joints. Fatigue testing machines used in this experiment were developed by the first author with Drs. Satoshi Yamada and Tatsuya Ojio, and their contribution is also greatly acknowledged. The fatigue testing machine enabled us to carry out fatigue tests very fast. Without them the fatigue tests would have taken several years. The experimental works were financially supported by Nagoya Expressway Authority.

\section{REFERENCES}

[1] Haagensen, P. J. and Maddox, S. J., "IIW Recommendations on Post Weld Improvement of Steel and Aluminum Structures”, 2007, XIII-2200r-07.

[2] Anami, K., Miki, C., Tani, H. and Yamamoto H., "Improving Fatigue Strength of Welded Joints by Hammer Peeing and TIG-dressing”, St. Eng./Earthquake Eng., 2000, JSCE, Vol. 17, No. 1, pp.67-78.

[3] Branco, C.M., Infante, V. and Baptista, R., "Fatigue Behaviour of Welded Joints with Cracks, Repaired by Hammer Peening”, Fatigue Fract. Engng. Mater. Struct., 2004, Vol. 27, pp. 785-798. 
[4] Roy, S., Fisher, J. W. and Yen, B. T., "Fatigue Resistance of Welded Details Enhanced by Ultrasonic Impact Treatment (UIT)”, International Journal of Fatigue, 2003, Vol. 25, No. 9-11, pp. 1239-1247.

[5] Tominaga, T., Matsuoka, K. and Satoh, Y., "Fatigue Improvement Method for Weld Repaired Crane Runway Girder by Ultrasonic Impact Treatment", Steel Construction Engineering, 2007, Vol. 14, No. 55, pp. 47-58. (in Japanese)

[6] Pedersen, M.M., Mouritsen, O.Ø., Hansen, M.R., Andersen, J.G. and Wenderby, J., "Comparison of Post Weld Treatment of High Strength Steel Welded Joints in Medium Cycle Fatigue”, International Institute of Welding, 2009, IIW Document XIII-2272-09.

[7] Yamada, K., Ishikawa, T., Kakiichi, T. and Li, H., "Extending Fatigue Life by Closing Crack Opening with ICR Treatment”, Fatigue Design 2009, 2009, November 25-26, Cetim, Senlis, France.

[8] Yamada, K., Kakiichi, T. and Ishikawa, T., "Extending Fatigue Life of Cracked Welded Joint by Impact Crack Closure Retrofit Treatment", International Institute of Welding, 2009, IIW Document XIII-2289 r1-09.

[9] Yamada, K., Ya, S., Baik B. and Torii, A., "Development of a New Fatigue Testing Machine and Some Fatigue Tests for Plate Bending", International Institute of Welding, 2007, IIW Document XIII-2161-07.

[10] Yamada, K., Osonoe, T. and Ojio, T., "Bending Fatigue Test on Welded Joint between Vertical Stiffener and Deck Plate, Steel Construction Engineering”, 2007, Vol. 14, No. 55, pp. 1-8.

[11] Japan Society of Steel Constructions (JSSC), "Fatigue Design Recommendations for Steel Structures", 1993. (in Japanese), 1995. (in English)

[12] Yamada, K. and Ya, S., "Review of Orthotropic Steel Deck Bridge and Some Fatigue Cracks and Retrofitting Measures in Japan", Orthotropic Bridge Conference, Sacramento, 2008, USA, pp. 531-542. 